\title{
Design and Implementation of a Robust Current Controller for Single-Phase Inverters Connected Electrical Network via a damped LCL filter for Renewable Energy Systems
}

\author{
J. A. Borges ${ }^{1}$, M. V. B. Mendonça ${ }^{2}$, F. A. M. Moura $^{2}$, M. R. M. C. Albertini ${ }^{2}$ \\ ${ }^{1}$ Universidade Federal de Uberlandia, Electrical Engineering Department Uberlandia- Minas Gerais, Brazil, \\ ${ }^{2}$ Universidade Federal do Triângulo Mineiro, Electrical Engineering Department, Uberaba- Minas Gerais, Brazil \\ julioaborges@hotmail.com, marcusmvbm@gmail.com, fabricio@eletrica.uftm.edu.br, madeleine.albertini@uftm.edu.br
}

\begin{abstract}
A renewable energy source plays an important role in electricity generation. Various renewable energy sources like wind, solar, geothermal, ocean thermal, and biomass can be used for generation of electricity and for meeting our daily energy needs. Energy from the sun is the best option for electricity generation as it is available everywhere and is free to harness. This paper deals with the design and implementation of a current controller for a single-phase voltage-fed inverter connected via an LCL filter. In this proposal, a single-phase micro-inverter connected to the power grid based on a complete bridge topology and the effects presented by the inclusion of a notch filter in the external voltage control mesh were analyzed. The proposed control improves the harmonic rejection capacity of the single phase inverters connected to the electric grid for application in photovoltaic panels, which is based on an alternative control structure and the proper selection of the LCL filter feedback current. The inclusion of a high order filter such as LCL in place of the traditional inductive filter provided greater capacity and attenuation of the unwanted components. However, the resonance from this filter impairs the stability of the system, requiring the inclusion of passive or active damping techniques. With the notch filter acting on the system, the current injected into the network had a substantially better total harmonic distortion index (THD), mainly due to the elimination of the $120 \mathrm{~Hz}$ ripple, meeting the requirements of international standards such as IEEE 1547.

In addition, the control of the system proved to be robust and efficient, keeping the steady state error close to zero even in the event of voltage sinking and variations in the frequency of the network.
\end{abstract}

\section{Key words}

Electric power. Harmonic distortion. Imbalance. Quality electricity. Renewable energies. photovoltaic system.

\section{Introduction}

The installed capacity of the Brazilian electric power matrix is of the order of 132 GWP, with hydroelectric power being predominant and representing approximately $65 \%$ of this capacity [1]. However, Brazil has an extensive area not covered by the public electricity network where more than 10 million people live. The conventional energy system does not have the structural conditions to meet this demand, but the country has several rural electrification programs through small autonomous systems, in which photovoltaic technology predominates [2]. Photovoltaic systems connected to the grid can be designed as systems to be integrated to buildings supplying energy demand and delivering excess energy to the grid or as large power plants that deliver all converted energy to the grid. The analysis of the behavior of photovoltaic installations connected to the grid is necessary for the knowledge and learning of these systems in order to develop the technology and make it a viable alternative within the energy system of the country[3-6].

In this paper, we discuss the design and implementation of a current controller for a single-phase inverter powered and connected through an LCL filter, see the configuration used in figure 1. In this proposal, a singlephase micro-inverter connected to the electric grid was analyzed based on a topology in complete bridge and the effects presented by the inclusion of a notch filter in the external voltage control mesh.



Fig. 1. PV system connected to the grid

The inverter c.c./c.a. converts the power into direct current from the photovoltaic arrangement in power, in alternating current that, under normal conditions (acceptable quality), will be injected into the electric distribution network. The development of electronic power technology has allowed a considerable increase in cc / cc conversion efficiency, together with increased reliability and cost savings. The inverters currently used in SFCR incorporate control functions that influence the operation of the system, such as: maximum power point follower, connection or disconnection of the network 
depending on the conditions of the same and the irradiance incident on the arrangement, energy and others. Static inverters use semiconductor devices for switching and operate in only two modes: cut mode (off) and saturation mode (on). Therefore, the output signal obtained is square. A square signal can be converted to a sinusoidal signal using power filters. The process to filter the harmonics closer to the fundamental requires large capacitors and coils that reduce system efficiency. The goal when developing inverters is to obtain output signals with low harmonic content and high power factor, which is possible by increasing the switching frequency of the semiconductors and properly filtering the output signal. One of the functions that any inverter must comply with is to regulate the output value. This regulation is basically achieved in three different ways: regulating the voltage before the inverter (DC / DC converters), regulating the voltage in the inverter itself through its control system or regulating the inverter signal through an autotransformer [7].

The inverters currently used in photovoltaic applications, as for the switching mode, can be divided into two categories: auto-switched and switched through the network. The inverters can act as a source of voltage and current source while the inverters are switched over the grid only as a current source. Auto-switched inverters can be used in grid-isolated or grid-connected photovoltaic applications, whereas grid-switched inverters can only be used in grid-connected applications [7]. Figure 1 shows the classification of inverters by principle of operation.

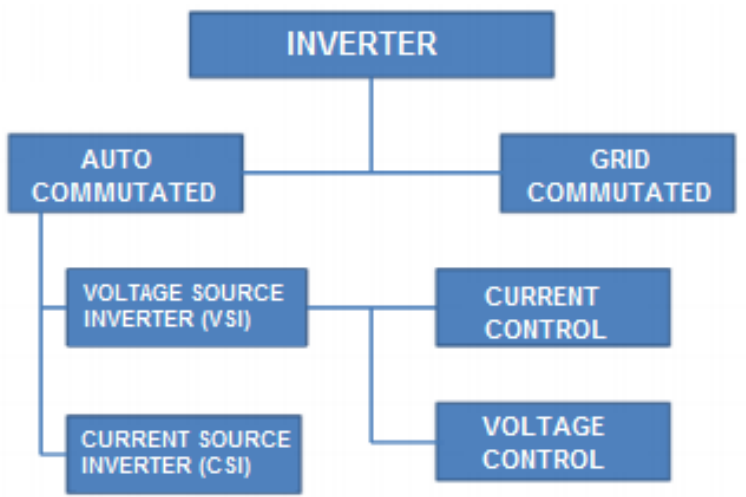

Fig. 2. Inverters' classification by principle of operation [7].

In auto-commutated inverters, the switching elements are semiconductors that can be driven or cut at any point in the cycle by means of a control terminal. The autoswitching inverters can operate independently, being activated only by a power source at the input. This type of inverter can be connected to the network since it is able to synchronize its output voltage alternating with the mains voltage. These devices operate in Pulse Width Modulation (PWM) and normally switch at high frequency and the output signal is sinusoidal, low harmonic content and high power factor. Networkswitched inverters are thyristor-based rectifier bridges and can only operate when alternating mains voltage is present. These inverters operate normally with low power factor and present a high level of harmonic distortion in their output signal. Since the introduction of new switching devices, the use of inverters to the thyristor has been reduced and is now restricted to very high power units (above $100 \mathrm{~kW}$ ) [7].

For purposes of further discussions, this article is structured as follows: the formulations methodologies, which will be used are presented in section 2. In section 3 , it is shown the control system used in this work. In Section 4, the simulations and análisis result are presented. In Section 5 the main conclusions are built on the problems studied here.

\section{Formulation methodologies}

In this section we present the projects calculated for each element

\subsection{LCL Filter Design}

The choice of an LCL filter at the output of the inverter circuit is due to factors such as the good reduction of electromagnetic interference (EMI), better attenuation at high frequencies and the reduction of size and cost when compared to the L filter [8]. However, it is necessary to design the controllers in order to reject possible oscillations due to the resonance of this filter, which is given by:

$$
\omega_{\text {res }}=\sqrt{\frac{L_{1}+L_{2}}{L_{1} L_{2} C}}
$$

The parameters required for the LCL filter design are: line-to-line RMS voltage (inverter output); phase voltage (inverter output); rated active power; dc-link voltage; grid frequency; switching frequency; and resonance frequency. Following the design procedures presented in [9], the values presented in Table I were obtained.

Table I. - Filter Parameters.

\begin{tabular}{|c|l|c|}
\hline$L_{1}$ & Inverter side inductor & $3.9 \mathrm{mH}$ \\
\hline$R_{1}$ & Inverter side resistor & $0.2 \Omega$ \\
\hline$L_{2}$ & Grid side inductor & $100 \mu \mathrm{H}$ \\
\hline$R_{2}$ & Grid side resistor & $0.015 \Omega$ \\
\hline $\mathrm{C}$ & Capacitor filter & $15 \mu \mathrm{F}$ \\
\hline$R_{c}$ & Damping resistor & $0.85 \Omega$ \\
\hline
\end{tabular}

\subsection{Link Capacitor Design}

Through the design of the DC link capacitor, it is possible to adjust the voltage ripple observed on the capacitor. Neglecting the losses of the inverter and considering that the voltage in the DC link is much greater than the voltage ripple, one can design the capacitor through the following equation:

$$
C_{d c}=\frac{P_{g}}{\omega V_{d c}^{2} r}
$$

Where $r$ is the ratio of the peak-peak voltage variation to the voltage across the capacitor. 


$$
r=\frac{2 \Delta_{v}}{V_{d c}}
$$

With the parameters of the inverter and to obtain a maximum voltage variation in the DC link of about $2 \%$ of the nominal value, a capacitor C_dc of $2000 \mu \mathrm{F}$ was obtained.

\subsection{Notch Filter Design}

It is worth mentioning the presence of a ripple with double grid frequency (in this case, $120 \mathrm{~Hz}$ ) in the DC link voltage that propagates to the reference current. This distortion in voltage implies a harmonic component in the output current of the network.

One of the ways to reduce the ripple effect on the output current is to use a notch filter when acquiring DC link voltage. The transfer function of this filter is shown in (4).

$$
G_{n o t c h}(s)=\frac{s^{2}+2 \xi_{1} \omega_{n} s+\omega_{n}^{2}}{s^{2}+2 \xi_{2} \omega_{n} s+\omega_{n}^{2}}
$$

Due to the characteristics of the transient response of the notch filter, its introduction to the system is done after a period of time, in order to reduce the influence of such a transient on the control response.

Para uma boa atenuação do ripple de $120 \mathrm{~Hz}$ utilizou-se os valores de $\omega_{n}=2 \pi .120 \mathrm{rad} / \mathrm{s}, \xi_{1}=0.008 \mathrm{e} \xi_{2}=1$.

\section{System Control}

\subsection{Current control structure}

In the literature, several types of current controllers are found for inverters connected to the network. Among them, PI (proportional-integral) and PID (proportional, integral and derivative) controllers stand out due to the ease of implementation.

For direct current (DC) systems, the PI and PID controllers show zero steady state error, ie, they have infinite gain at zero frequency. Already in the situation of AC systems, these controllers are used in a synchronous reference, in which the $\mathrm{AC}$ variables are converted to $\mathrm{CC}$ variables through rotational transformations. However, such transformations may introduce amplitude and phase errors. Moreover, the infinite gain at zero frequency together with the integrator action can lead to saturation, damaging the response.

One way to avoid synchronization problems is to use the proportional-resonant $(\mathrm{P}+\mathrm{RES})$ controller, which has infinite gain in the tuning frequency $(\mathrm{eg}, 60 \mathrm{~Hz})$. It operates with stationary reference and allows to achieve virtually the same results presented by the PI controller in synchronous reference, both in steady state and transient regime [10]. Since this controller does not have infinite gain at the zero frequency, it is immune to the $\mathrm{CC}$ value due to imprecision of the current sensors.

The ideal proportional-resonant compensator has the transfer function shown in (5), where k_p is the proportional gain, $\mathrm{k}_{-} \mathrm{i}$ is the integral gain and $\omega_{-} 0$ is the angular frequency of synchronization. The difficulty related to the implementation of the ideal integrator or an equivalent lossless $\mathrm{AC}$ transfer function leads to the use of a non-ideal function presented in (6), which corresponds to an ideal integrator approach to a low-pass filter [10]. ]. Low $\omega$ c values make the filter more sensitive to frequency variations, which leads to slower transient responses. In practice, wc values between 5 and $15 \mathrm{rad} / \mathrm{s}$ present good responses [11]. The addition of an extra term to the ideal proportional-resonant transfer function allows adjustment of transient response behavior [12]. This new transfer function is presented in (7).

$$
\begin{gathered}
G_{P R}(s)=k_{p}+\frac{2 k_{i} s}{s^{2}+\omega_{0}^{2}} \\
G_{P R}(s)=k_{p}+\frac{2 k_{i} \omega_{c} s}{s^{2}+2 \omega_{c} s+\omega_{0}^{2}} \\
G_{P R}(s)=k_{p}+\frac{2 k_{i 1} s}{s^{2}+\omega_{0}^{2}}+\frac{2 k_{i 2}}{s^{2}+\omega_{0}^{2}}
\end{gathered}
$$

In order to obtain a sinusoidal current and synchronized with the mains voltage at the inverter output, the nonideal proportional and resonant controller $(\mathrm{P}+\mathrm{RES})$ was used. The block diagram of the current control loop is illustrated in Figure 3, where i_ref is the reference current, G_PR (s) is the current compensator, G_id (s) is the transfer function related to the output current to the cyclic ratio and $\mathrm{H} \_\mathrm{i}$ is the gain of the current transducer.



Fig. 3. Block diagram of the current control loop.

The adjusted parameters for the non-ideal resonant proportional controller are shown in Table II.

Table II. - PR Parameters.

\begin{tabular}{|c|l|c|}
\hline$k_{p}$ & Ganho proporcional & 2 \\
\hline$k_{i}$ & Ganho integral & 200 \\
\hline$\omega_{c}$ & Largura de banda & $10 \mathrm{rad} / \mathrm{s}$ \\
\hline$\omega_{0}$ & Frequência fundamental & $377 \mathrm{rad} / \mathrm{s}$ \\
\hline
\end{tabular}

\subsection{Voltage control structure}

The voltage controller composes the external control grid used in the inverter system. Since the reference for the voltage control is a DC signal, the use of an integral 
proportional compensator is adequate, in view of zerosteady zero frequency error. The transfer function of the PI compensator is shown in (8)

$$
G_{P I}(s)=k_{p v} \frac{\left(s+1 / T_{i}\right)}{s}
$$

By comparing the DC link voltage of the system with the reference value, the error signal is applied to the integral proportional compensator which, in turn, generates as output the reference current amplitude for the internal current loop.

For the voltage controller, the set parameters are shown in Table III.

Table III. - PI Parameters.

\begin{tabular}{|c|l|c|}
\hline$k_{p i}$ & Proportional Gain & 1.16 \\
\hline$T_{i}$ & Integration Time & 0.012 \\
\hline
\end{tabular}

\section{Simulations and results}

With the power circuit modeled and the designed controllers, the computational simulations were carried out with the purpose of verifying the operation and evaluation of the performance of the proposed system. For this purpose, the PSIM software was used. Figures 4, 5 and 6 show the control circuit, MPPT control and power circuit developed in the software, respectively.

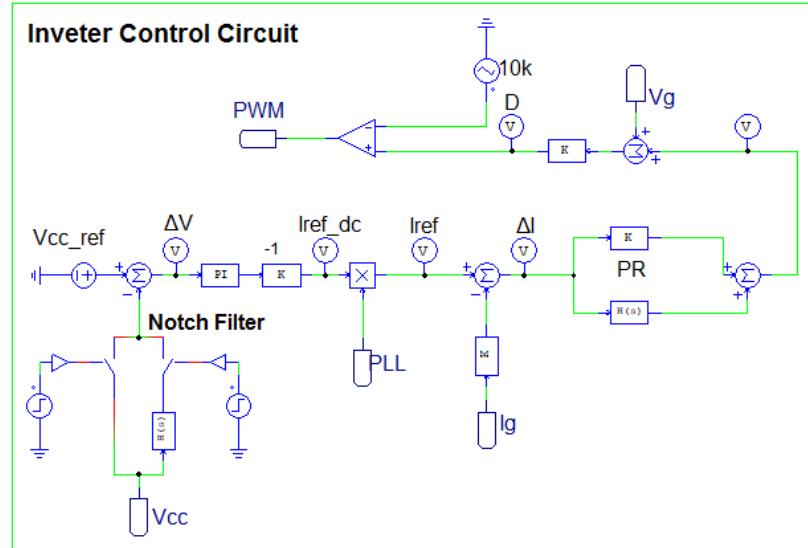

Fig. 4. Control circuit on PSIM.

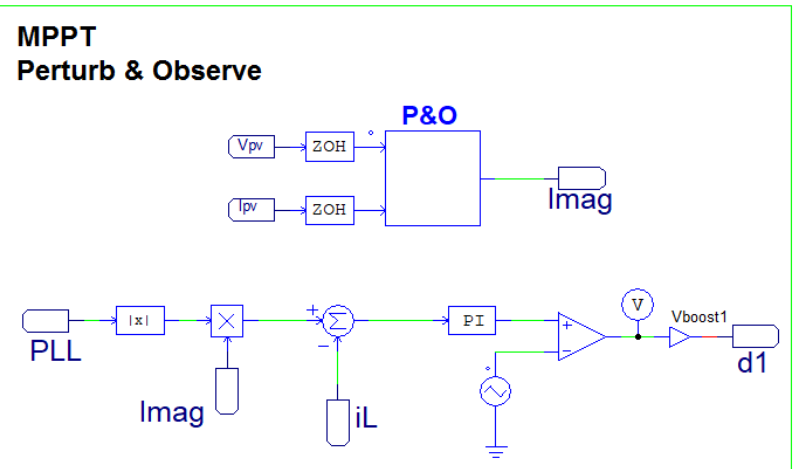

Fig. 5. MPPT structure on PSIM.

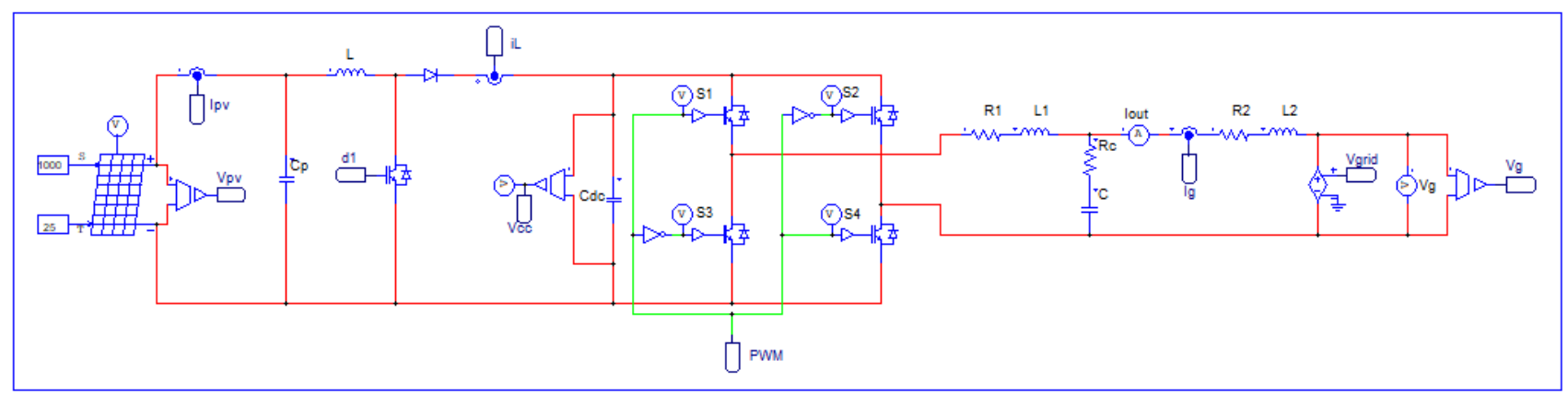

Fig. 6. Power circuit on PSIM.

Initially, in order to prove the efficiency of the projected notch filter, the reference signal generated by the voltage loop and the output current before and after the entrance of the notch filter is shown in Figure 7. Figures 8 and 9 show the THD of the output current before and after the input of the notch filter.

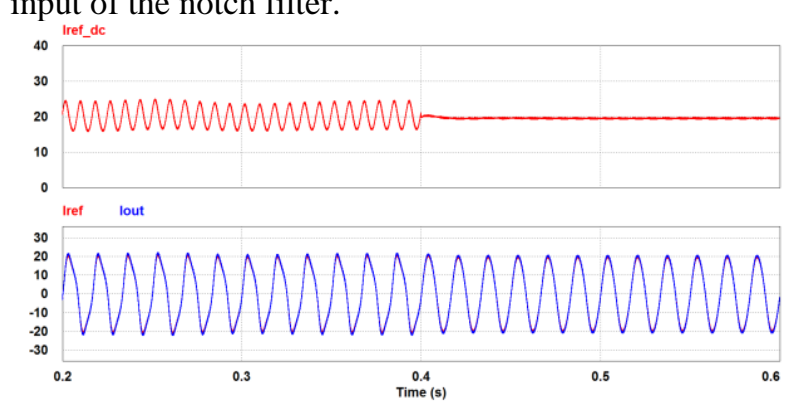

Fig. 7. Output current before and after the Notch filter.

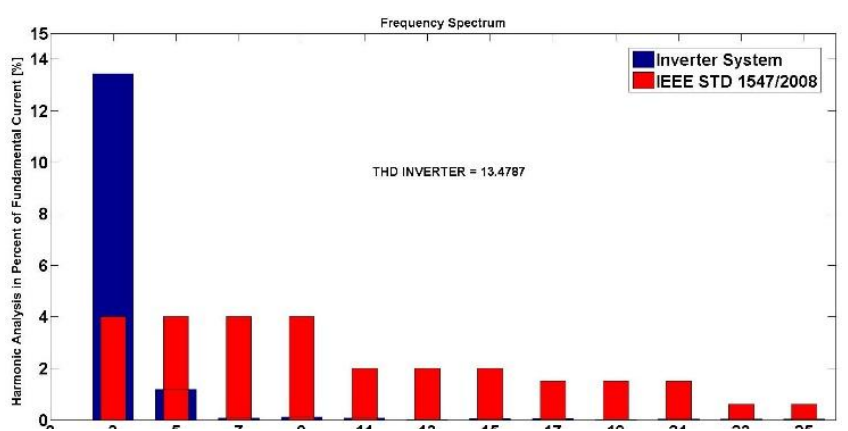

Fig. 8. Current THD without Notch filter. 


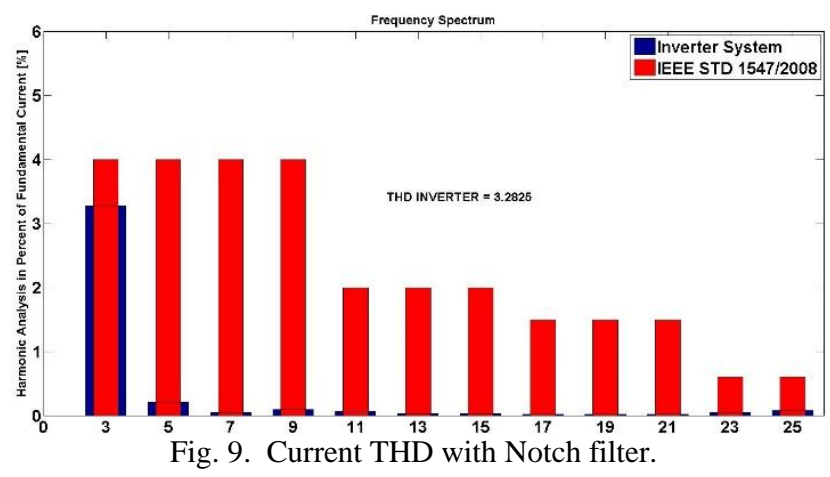

As shown in the figure above, the $120 \mathrm{~Hz}$ ripple observed on the DC link $\left(I_{\text {ref_dc }}\right)$ propagates to the reference current $\left(I_{\text {ref }}\right)$. This distortion in the reference implies harmonic contents in the current of the output inductor $L_{2}$ After switching the notch filter on the feedback loop at time $0.4 \mathrm{~s}$, the reference current amplitude no longer shows the ripple and the output current becomes a sine wave with low harmonic content.

In a second moment, a disturbance in the network frequency was simulated, assuming a variation of $1 \mathrm{~Hz}$ below and above the nominal frequency of $60 \mathrm{~Hz}$, as shown in Figure 10. It can be observed that the frequency variation did not match sudden changes in behavior of the system, showing that the PLL projects together with the control of the system managed to compensate for such variation

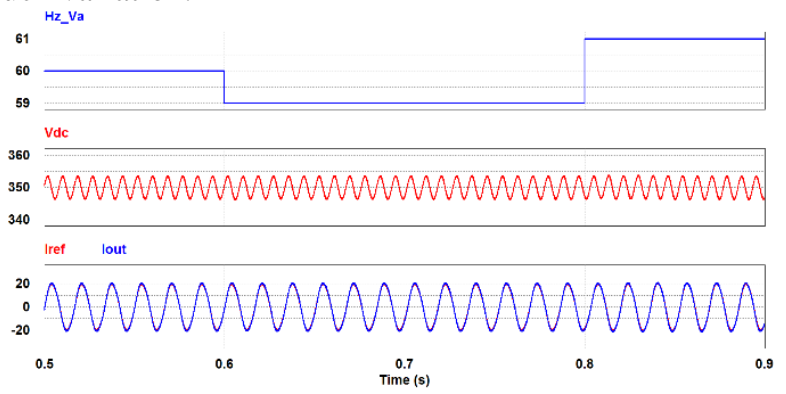

Fig. 10. Grid frequency variation.

Finally, the response of the system to a sinking in the mains voltage of $50 \%$ of the nominal value for 5 cycles was verified, as shown in Figure 11.

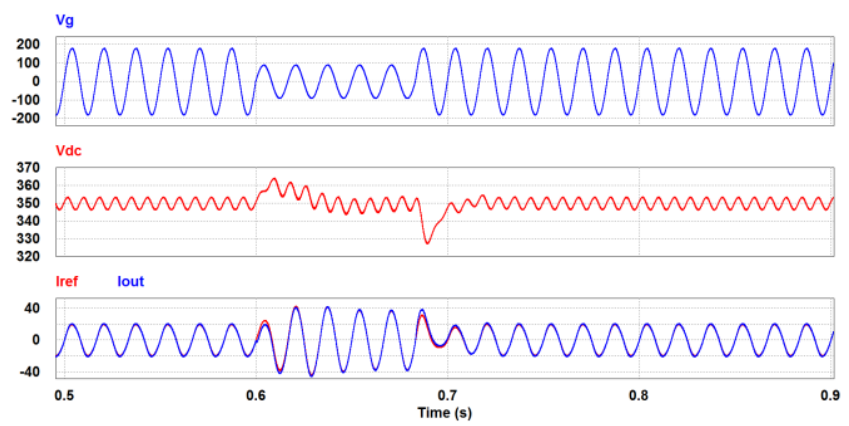

Fig. 11. Voltage sag to $50 \%$ of nominal voltage.

In this situation it is observed that there was a transient with a peak amplitude greater in the reference current. However, the control system proved to be able to compensate for sinking by maintaining the sinusoidal current.
This paper analyzed a single-phase microinverter connected to the electric grid based on a complete bridge topology and the effects presented by the inclusion of a notch filter in the external voltage control mesh.

The inclusion of a high-order filter such as LCL in place of the traditional inductive filter provided greater capacity and attenuation of the unwanted components. However, the resonance from this filter impairs the stability of the system, requiring the inclusion of passive or active damping techniques [13].

With the notch filter acting on the system, the current injected into the network had a substantially better total harmonic distortion index (THD), mainly due to the elimination of the $120 \mathrm{~Hz}$ ripple, meeting the requirements of international standards such as IEEE 1547.

In addition, the control of the system proved to be robust and efficient, keeping the steady state error close to zero even in the event of voltage sinking and variations in the frequency of the network.

\section{References}

[1] AL-MASRI, Hussein M.; EHSANI, Mehrdad. Feasibility investigation of a hybrid on-grid wind photovoltaic retrofitting system. IEEE Transactions on Industry Applications, v. 52, n. 3, p. 1979-1988, 2016.

[2] TEODORESCU, Remus et al. Grid converters for photovoltaic and wind power systems. John Wiley \& Sons, 2011.

[3] MAGHAMI, Mohammadreza; HIZAM, Hashim; GOMES, Chandima. Impact of dust on solar energy generation based on actual performance. In: Power and Energy (PECon), 2014 IEEE International Conference on. IEEE, 2014. p. 388- 393.

[4] GARRAOUI, Radhia; HAMED, Mouna Ben; SBITA, Lassaad. Comparison of MPPT algorithms for DC-DC Boost converters based PV systems using robust control technique and artificial intelligence algorithm. In: Systems, Signals \& Devices (SSD), 2015 12th International Multi-Conference on. IEEE, 2015. p. 1-6.

[5] MOHAMMED, S. Sheik; DEVARAJ, D. Simulation of incremental conductance MPPT based two phase interleaved Boost converter using MATLAB/simulink. In: Electrical, Computer and Communication Technologies (ICECCT), 2015 IEEE International Conference on. IEEE, 2015. p. 1-6.

[6] HU, Boyang; SATHIAKUMAR, Swamidoss. Current ripple cancellation of multiple paralleled Boost converters for pv/battery charging system with mppt. In: Innovative Smart Grid Technologies Asia (ISGT), 2011 IEEE PES. IEEE, 2011. p. 1-6.

[7] BARBI, Ivo. Modelagem de conversores CC-CC. Florianópolis: Edição do autor, 2015.

[8]Yepes, A.G., Digital Resonant Current Controllers for Voltage Source Converters, Doctoral Dissertation, University of Vigo, 2011.

[9]Aleksandr Reznik, Marcelo Godoy Simoes, Ahmed Al-Durra, LCL Filter Design and Performance Analysis for Grid-Interconnected Systems,IEEE Transactions on

\section{Conclusion}


Industry Applications,Vol.50, N.2,March-April,2014, pp1225-1232.

[10]Daniel Nahum Zmood and Donald Grahame Holmes,Stationary Frame Current Regulation of PWM InvertersWith Zero Steady-State Error, IEEE Transations On Power Electronics, Vol. 18, No. 3, May 2003, pp814822.

[11]R. Teodorescu, F. Blaabjerg, M. Liserre and P.C. Loh, Proportional-resonant controllers and filters for grid-connected voltage-source converters, IEE Proc.Electr. Power Appl., Vol. 153, No. 5, September , 2006
[12]Alon Kuperman, Proportional-Resonant Current Controllers Design Based on DesiredTransient Performance, IEEE Transations On Power Electronics, Vol. 30, No. 10, October 2015, pp5341-5345.

[13]S. J. M. Machado. "Uma proposta de controle com alta capacidade de rejeição harmônica para inversores monofásicos conectados à rede elétrica através de filtro LCL amortecido para sistemas de energia renovável”. Dissertação de mestrado apresentado na UEL, Londrina/PR, 2016. 